\title{
KEEPING THE FIRE BURNING
}

\author{
STRATEGIES TO SUPPORT SENIOR FACULTY
}

\author{
Michael J. Zeig, Roger G. Baldwin \\ Michigan State University
}

Recent reports indicate that at some colleges and universities, as many as one in three professors are age sixty or older. This increase in senior faculty raises the question of what institutions do to support this large and important cohort. Historically, faculty development programs have focused on early-career faculty, with less attention paid to more seasoned professors. Based on a national web-based investigation, this chapter reviews the strategies some institutions have implemented to support senior faculty. It also provides recommendations for how senior faculty and their administrator colleagues can provide new meaning and purpose to this phase of academic life.

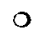

As baby boomers approach retirement age, many organizations, including higher education institutions, face an increasingly older workforce. While this means that some organizations will face high turnover rates in the coming years, higher education institutions face a unique challenge in dealing with an aging professoriate. The growing number of older professors, combined with the end of mandatory retirement, an increasing life span, economic uncertainty, and a love for their profession, is resulting in a large number of older professors putting off retirement. 
In fact, the Chronicle of Higher Education recently reported, "At some universities ... more than one in three tenured or tenure-track professors are now 60 or older" (June 2012, para. 4). Colleges and universities may face an increasing number of retirements as professors continue to age, but they also face the question of how to support older professors who remain employed at their institutions.

In The Vitality of Senior Faculty Members: Snow on the Roof-Fire in the Furnace, Bland and Berquist (1997) argued that senior professors are a vital force with much to contribute to their institutions and profession. This chapter explores the varied ways in which institutions currently support the distinctive needs of senior faculty. There are many ways to identify a senior faculty member through indicators such as rank, age, and years of service. For this reason, definitions vary across institutions. For the purposes of this chapter, we define a senior faculty member as an individual who is fifty-five years or older with many years (fifteen or more) of service in the academic profession.

\section{Brief History of Faculty Development}

Historically faculty development programs have focused primarily on early-career, tenure-track faculty. The needs and concerns of early-career faculty have been chronicled in great depth (Austin, 2003; Boice, 1992; Brown, 2006). Although early-career faculty encounter many challenges during the beginning years of their employment, they also often receive significant start-up funds for research projects, protection from timeconsuming committee work, mentoring, and other forms of development support for their teaching. Colleges and universities often view earlycareer faculty as one of their highest priorities and offer many programs and services designed to address early-career challenges.

In recent years, interest in faculty development has expanded to include a focus on midcareer faculty. Baldwin and Chang (2006) identified strategies colleges and universities have implemented to support midcareer faculty, including support to move research in new directions or develop new teaching skills. Baldwin, DeZure, Shaw, and Moretto (2008) studied midcareer faculty at a research university and outlined distinctive challenges these professors face, including the lack of a clear direction following the attainment of tenure. The researchers also identified support strategies that institutions, especially department chairs, can use to support faculty in the middle of their careers.

Support for faculty development now extends beyond the formal boundaries of an academic career. For example, many doctoral 
institutions have created their own future faculty preparation programs (Preparing Future Faculty, 2012) as a means to prepare graduate students more thoroughly for a faculty career by enhancing the culture of doctoral education and the professional socialization process (Austin, 2002; PruittLogan \& Gaff, 2004). On the back end of the career is a new focus on how to support faculty in their transition to retirement along with initiatives to make the retirement years engaging and fulfilling. In a nationwide study, Baldwin and Zeig (2012) identified 180 retired faculty organizations providing a range of services and activities for emeritus professors. There is also a national organization, the Association of Retirement Organizations in Higher Education (2012), dedicated to supporting campus efforts to serve retired faculty.

The many ways faculty are supported from their time in graduate school through their early- and middle-career phases and in retirement are all important to faculty careers. Unfortunately, much less attention has been paid to faculty during the latter stages of their employment despite the fact that faculty in their fifties and sixties may still work for another ten to fifteen years. Although the needs of senior professors may be different from those of younger faculty, these needs should not be discounted or ignored. If institutions are serious about supporting strong faculty performance at all career stages, it is important to consider the needs of senior late-career faculty and examine strategies designed to support this important group of professors. Gappa, Austin, and Trice (2007) argued that "in order to work creatively and effectively in a rapidly changing context, faculty must engage in continuous learning so as to constantly expand their repertoires of talents and skills" (p. 84). Colleges and universities have an important role to play in facilitating this continual learning and development.

\section{Needs of Senior Faculty}

The professional needs of senior faculty often differ from those of earlyor midcareer faculty. Although some senior faculty may still be interested in pursuing goals comparable to those of their junior colleagues, others may be focused on new aspects of their career. Bland and Berquist (1997) indicated that senior faculty often wish to contribute to their institutions in different capacities such as renegotiated teaching duties, service roles, or mentoring new faculty members, which may differ from earlier priorities in their careers when they were more focused on their own research productivity. Berberet, Bland, Brown, and Risbey (2004) found that many senior faculty are interested in more flexible workload arrangements, as well as contributing to their institutions through service 
activities in areas where they may have well-developed skills and expertise. In addition, some senior faculty are interested in having opportunities to learn entirely new roles through on-campus "internships" or other opportunities that allow them to explore new ways to contribute to their institutions in administrative or other professional roles (Berberet et al., 2004).

Besides looking for new ways to contribute to their institutions, senior faculty may also desire support services more closely aligned with their distinctive needs. Bataille and Brown (2006) argued that senior faculty are particularly sensitive to resource allocation issues and may have a strong desire for access to research funds to jump-start or move their research in new directions. In terms of teaching support, Schuster and Finkelstein (2006) noted that many senior faculty are interested in learning new instructional technologies but do not receive proper training on how to integrate those technologies in the classroom. Trower (2011) found that many senior faculty desire more support and encouragement from administrators and peers to help them "remain vital, productive, and engaged" (p. 11). This can include better communication about expectations and priorities and continuity in those expectations even during leadership changes within the university (Trower, 2011). Despite the growing documentation of the needs of senior faculty, little is known about how institutions actually support faculty in the latter stages of their careers.

\section{Support for Senior Faculty}

In order to gain a better understanding of the current forms of support for senior faculty, we conducted a national web-based search for senior faculty development programs, policies, and services. The search was conducted during spring 2012 using search terms such as "senior faculty programs," "senior faculty development," and "support for late-career faculty." We focused on identifying institutions with forms of support targeted specifically at senior faculty, although institutions often defined senior faculty differently. We did not review monetary retirement incentives or buy-outs since those options are focused on encouraging retirements rather than developing faculty.

We discovered that many faculty development offices indicate they offer programs for faculty from early-through late-career stages, although they often do not make clear specifically how senior faculty are supported differently from faculty at other career stages. It is less common for institutions to maintain programs and services specifically aimed at senior 


\section{Table 5.1 Examples of Institutional Support for Senior Faculty}

\section{Development programs}

Carleton College (https://apps.carleton.edu/handbook/facultyapp/?policy_id= 864379\#864439)

Marquette University (http://www.marquette.edw/phil/documents/SeFacRevPro tocols.pdf)

University of Georgia (http:/www.ctl.uga.edu/faculty/ct_senior_teaching_fellows)

Western Michigan University (http://www.wmich.edu/facdev/Programs /Communities.html)

\section{Mentoring}

University of Michigan (http://www.provost.umich.edu/faculty/faculty_mentor ing_study/ideas.html)

University of North Carolina-Greensboro (http://www.uncg.edu/tld/mentoring/)

\section{Research support}

Dartmouth College (http://www.dartmouth.edu/ dof/jif_sfg_2011 memo_rev .pdf)

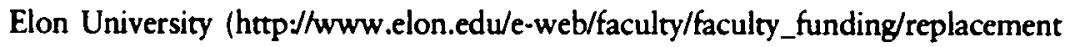
.xhtml\#senior)

Georgetown University (http://admin.maincampusresearch.georgetown.edu /index.php/Grant-Senior_Faculty_Research_Fellowships)

Illinois State College of Fine Arts (http://www.cfa.ilstu.edu/faculty_staff/grants .shtml)

\section{Workload adjustment}

Appalachian State University (http://www.hubbard.appstate.edu/senior-faculty)

Drake University (http://www.drake.edu/academics/policies/pdf/srfacultystatus .pdf)

\section{Recognition}

Ohio State University (http:/www.osu.edu/universityawards/2012/scholar.html) University of Michigan (http:/www.rackham.umich.edu/faculty_staff/awards /faculty_awards/henry_russel_lectureship/)

faculty. Our search did, however, identify five main categories of support provided for senior faculty: development programs, mentoring, research support, workload adjustments, and recognition. We highlight examples of each form of support within each category. We chose the examples to highlight a variety of types of well-developed programs and services from multiple institutional types. Table 5.1 provides web URLs of selected examples within each category. 


\section{Development Programs}

One method institutions use to support senior faculty is through development programs designed to address the unique interests and needs of senior faculty. Many of these programs provide forums for reflecting on professional roles, duties, and future directions. For example, Carleton College's (2012) Senior Faculty Development Forum "provides a regular opportunity for faculty who are Full Professors to reflect on teaching, scholarship, creative and service activities and to plan a course of professional development for the future" (para. 3). These reflective activities often focus on honing new skills related to teaching and learning. At Western Michigan University, the faculty development office established senior faculty learning communities to discuss teaching innovations. The University of Georgia's senior teaching fellows program focuses on sharing ideas across disciplines related to undergraduate instruction. This program also involves creating an instructional project "to strengthen courses and teaching methods in each participant's academic department" (University of Georgia Center for Teaching and Learning, 2012, para. 2).

Some institutions include department chairs in a reflective developmental review process with senior faculty, with the emphasis clearly on professional development, not evaluation. At King's College, the senior faculty development program provides senior faculty members an opportunity to create a professional development plan outlining longterm goals and how those goals align with the needs of the department and college. Similarly, Marquette University's (2012) philosophy department maintains a policy for reviewing senior faculty that encourages a "frank and candid discussion regarding the enhancement of a faculty member's career, working conditions, and satisfaction at Marquette" (para. 1).

Some development programs include monetary support. The programs at Carleton and Georgia provide faculty members with five hundred dollars and two thousand dollars, respectively, for supporting faculty members' professional development or for completing projects related to their development goals. Although King's College does not indicate a specific monetary amount, its program does make a general commitment to provide faculty members with resources to achieve mutually beneficial goals within their development plans. These funds, although often in small amounts, send an important message to senior faculty that their continued developmental needs are not only recognized but also supported financially. 


\section{Mentoring}

Another way institutions use senior faculty is to involve them in mentoring their junior colleagues. These programs typically pair an experienced, tenured faculty member with a newly hired assistant professor. The senior faculty member may provide guidance to the newer professor on teaching, research, or other professional roles. Although mentoring programs usually emphasize benefits to the junior partner, these programs can also offer developmental opportunities for the senior faculty mentor. For example, at the University of North Carolina-Greensboro, the New Faculty Mentoring Program is described as a mutually beneficial opportunity. The senior faculty mentors receive summer training in mentoring, meet monthly with the other senior faculty mentors, and receive five hundred dollars in an academic expense account. In this program, the senior faculty have an opportunity to grow and develop as mentors. This opportunity may help them beyond their immediate mentoring of a junior colleague and can also help them in future student mentoring activities as well.

At the University of Michigan, the provost's office provides a list of ideas related to mentoring intended for deans, associate deans, and department chairs to consider in establishing their own mentoring programs. Among the suggestions, the office recommends that senior faculty who provide mentoring services receive course release time or appropriate recognition during annual reviews for their mentoring activities as a university service, or both. Ensuring that mentoring activities are beneficial to both the mentor and mentee can help mentoring become more than an additional task for senior faculty. It also can provide an opportunity for senior faculty to reflect on their years of practice and, through mentoring, learn from their junior colleagues as well. This can be particularly important in fields with quickly changing technological advances, such as journalism, computer science, and marketing. When senior faculty take part in co-mentoring they can learn from their younger colleagues about the latest advances in their fields and innovative research methods while they help their junior colleagues learn about teaching, institutional service, and professional norms.

\section{Research Support}

Support for research activities is another way institutions can aid senior professors. At some institutions these awards are fairly straightforward. At Elon University, senior faculty research fellowships are available for 
post-probationary faculty with seven or more years of experience. At the Illinois State College of Fine Arts, a senior faculty research award program provides research funds of up to four thousand dollars for senior faculty. Other institutions provide awards that grant release time for senior faculty. Dartmouth College (2012), for example, "provides one term of released time for senior members of the faculty who have established reputations in a given field or are venturing into a new field outside their accustomed area of study" (para. 4). At Georgetown University, senior faculty research fellowships are provided to allow seasoned professors to pursue a project in the creative arts.

\section{Workload Adjustment}

During the latter stages of their career, some professors may wish to reallocate the amount of time they spend on certain activities or decrease their work commitment partially. Appalachian State University's (2012) faculty development office website states, "It is not uncommon for senior faculty who have firmly established a national reputation in their field to become less interested in scholarship and more interested in service to the University or profession, and/or mentoring students and younger colleagues" (para. 5). Appalachian State provides opportunities for senior faculty to develop new teaching skills or take on new responsibilities to mentor and advise students. These opportunities can provide a new sense of purpose and help energize senior faculty.

Drake University offers another way to adjust one's workload in the latter stages of the career. At Drake, senior faculty can participate in a program that allows them to teach a two-thirds load at two-thirds pay for up to two years. This program differs from Drake's retirement benefits program, which is a more traditional retirement incentive program. Instead, its senior faculty status program allows faculty wishing to remain productively engaged in the latter stages of their career to begin to taper off responsibilities while still remaining an active part of the academic workforce.

\section{Recognition}

Several institutions honor senior faculty through awards and other forms of recognition. Although awards are not developmental in and of themselves, many of the awards are signs of appreciation of senior faculty for their years of hard work and service to the institution. At some institutions, awards are combined with a monetary prize. At the University of 
Michigan, the Henry Russel Lectureship is considered among the highest honors a senior faculty member can receive. Recipients are selected by a campus committee and formally approved by the board of regents, an indication of the importance the university places on this award. Honorees receive a monetary prize of two thousand dollars and deliver a lecture to the campus community. At Ohio State University (2012), the distinguished scholar award "recognizes exceptional scholarly accomplishments by senior professors who have compiled a substantial body of research" (para. 1). Along with their formal recognition and award, recipients receive a three-thousand-dollar and a twenty-thousand-dollar research grant.

\section{Sizing Up Support for Senior Faculty}

Senior faculty can provide many benefits to their institutions. Yet our research shows that institutions provide limited forms of support specifically designed to help senior faculty continue to grow, develop, and prosper. The examples we have presented highlight some of the ways institutions try to support senior faculty members. From the senior faculty initiatives we identified, several themes emerge about the purpose and structure of senior faculty support programs and policies:

$\checkmark$ The lack of a consistent definition of senior faculty means that some "senior" faculty programs are not designed specifically for the latecareer senior faculty member whom we define as fifty-five years or older with fifteen or more years of experience in the academic profession.

o Programs often focus more on recognition or how to use senior faculty rather than how to help senior faculty grow and develop.

o There are multiple ways to support senior faculty development at different levels within an institution.

o Very few institutions take a comprehensive developmental approach to addressing the distinctive needs of senior faculty.

Many of the "senior" faculty programs we reviewed may not actually serve the most seasoned faculty. The programs reviewed offer many different definitions of senior faculty ranging from any associate or full professor to individuals who are within a few years of retirement. It is possible that an individual could be an associate professor by his or her midthirties and would need much different support from a long-serving professor who is fifty-five or older. It is noteworthy that some institutions 
develop "senior" faculty programs, but the lack of a consistent definition about who senior faculty members are makes it difficult to truly determine how many support services exist for late-career faculty. Furthermore, this lack of a precise definition may lead institutions and departments to overlook the distinctive professional needs of this important group of faculty.

Our research revealed that many programs for senior faculty are not intentionally developmental in nature. Mentoring, for example, can be a mutually beneficial experience. However, mentoring programs usually emphasize support of junior faculty. Honors and recognition, while nice to receive, are ways to acknowledge senior faculty contributions, but not necessarily to support faculty in a new phase of their career. Awards programs may also neglect long-serving professors who do not stand out from their colleagues for their professional achievements. These types of support services are important to continue, but they are not necessarily sufficient to meet the diverse developmental needs of senior faculty. In contrast, some of the programs we reviewed that encourage senior faculty to reflect on their careers and identify new strategies for remaining productive in teaching, research, and service provide opportunities for learning and growth more consistent with the needs and desires of faculty in the latter stages of their careers.

We also found a variety of ways to support senior faculty across different levels of an institution. We identified senior faculty support services offered out of the provost's office, at the department level, and through faculty development offices. For example, the provost's office at the University of Michigan serves as a repository of information on mentoring programs that deans and chairs across campus can tailor to support the senior faculty in their academic units. Marquette University's philosophy department conducts a developmental review of senior faculty work conditions and satisfaction. At other institutions, such as Appalachian State and Western Michigan, faculty development offices take the lead in coordinating support for senior faculty. This variety of service options at different levels across an institution demonstrates the multiple avenues through which senior faculty can be supported. Every institution has its own unique culture. However, with a variety of options available to support senior faculty, each institution can develop ways to support long-serving professors that are consistent with its mission and culture.

Finally, it is clear from our study that notable strategies are being employed at some institutions to support senior faculty, but this support is not widespread. For example, Berberet et al. (2004) argued that some senior faculty may desire opportunities to learn and develop new skills 
through internships that allow them to explore new career opportunities, but we did not find any explicit examples of this practice. Some of the development programs we found provide opportunities for personal reflection and discussion with peers and chairs, but not necessarily opportunities to explore new professional roles as part of a formalized program. In addition, while the research support provided for senior faculty at some institutions is beneficial, it is not always targeted specifically to meet the research needs of faculty late in their careers. Bataille and Brown (2006) argued that many senior faculty desire research funding specifically enabling them to jump-start research in new areas. This may require different types of institutional funding programs from what is typical of traditional in-house grants that often favor faculty with well-developed research ideas and a record of achievement in a particular specialty area. Overall, the forms of support provided for senior faculty that we identified are a good starting point for addressing the needs of this cohort of faculty, but they do not address all the needs of senior faculty and are not prevalent across many institutions.

\section{Recommendations}

Although the growing number of senior faculty at many colleges and universities often raises the question of how institutions can best maintain a steady flow of academic talent, it should also provide an opportunity for institutions to consider how they can best support their current faculty even at the latter stages of faculty careers. Blaisdell and Cox (2004) argued that it is important not to automatically assume that the cohort of senior faculty is "somehow lacking, deficient, or not fully vital" (p. 138). There may be some senior faculty members who are beyond their greatest years of productivity and may need to be gently nudged toward retirement, but other senior faculty members have much to contribute to their institutions, students, and academic fields. Developing support programs, policies, and services for this group of faculty, even in a limited fashion, can help ensure that senior faculty have the tools necessary to be productive and fulfilled in their final years of employment. In order for programs to be successful, there are important issues for both faculty and administrators to consider. We offer the following recommendations:

\section{Recommendations for Faculty}

o Be reflective about your career. Faculty entering the latter stages of their careers should take time to consider what their goals are for their remaining years of service. Many senior faculty find new 
priorities during the latter stages of their careers. Senior faculty should be explicit about outlining what their priorities are and what support they need to achieve those priorities. Priorities could include engaging in more undergraduate teaching and mentoring or concluding a long-term research or writing project prior to retirement. Regardless, senior faculty must reflect on their priorities before they are able to identify what support services they need.

- Reconsider what success means in late career. For many highly productive senior faculty, the latter stages of their career may result in the need to redefine success. For example, faculty winding down their academic careers may find it difficult to pursue or receive as many major grant awards. While this may become a source of dissatisfaction for some faculty members, it is important for those faculty to find other ways to contribute professionally. Senior faculty may be able to use their experience and knowledge to serve in other ways. They may find a renewed sense of vitality in teaching, mentoring, working with alumni, or supporting institutional advancement. It is important for senior faculty to understand that they can continue to be contributing members of the academy in the latter stages of their careers even if in new and different ways than they were previously.

- Seek out co-mentoring opportunities. Much of the discussion on mentoring focuses on how senior faculty can mentor younger professors and students. These opportunities are important, but it is also important for senior faculty to find their own mentors, often from a younger cohort of colleagues. Younger professors can help senior faculty learn new technologies, new teaching techniques, and the latest trends in their fields. Mentoring should be a two-way street: senior faculty often have as much to learn as they have to offer others.

o Recognize that it may take faculty initiative to secure proper departmental or institutional support for senior faculty. Since most faculty development support is aimed at early-career faculty, senior faculty can often be overlooked. Senior faculty desiring more development and support for teaching, research, or other professional endeavors should be explicit with their department chairs and deans about what support they need. Many of the support services senior faculty may desire, such as co-mentoring opportunities, senior faculty learning communities, or teaching technology workshops, can be accomplished at little or no cost and could be spearheaded by 
senior faculty themselves as a starting point. While costs are always a concern, there are many ways to support the growth and development of senior faculty peers on a smaller scale, with the hopes of growth in these programs in the future if successful and costeffective.

\section{Recommendations for Chairs, Deans, and Faculty Development Offices}

- Recognize that senior faculty are not a homogeneous group. Some senior faculty may remain highly productive in their research, while others may wish to focus more on teaching or other roles in the latter stages of their careers. It is important to recognize these differences and identify ways for all senior faculty to contribute productively to the institution.

- Help senior professors rejuvenate and revitalize their interests. It would be a mistake to view senior faculty as professionals past their prime who merely need to show up to teach their required courses and do little else. Viewing senior faculty in this light may lead to a self-fulfilling prophecy. In reality, with appropriate support and development opportunities, senior faculty can remain an engaged and vital part of the academy. This may require negotiation with individual senior professors to develop new professional goals and determine what resources, such as money, time, and learning opportunities, will be necessary to reach these goals.

o Recognize the difference between offering generic support services for faculty across the career and support targeted specifically for faculty in the latter stages of their careers. Many colleges and universities offer teaching and research support programs regardless of faculty age or rank. It is important, however, just as it is with earlycareer faculty, to offer forms of support specifically responsive to the circumstances and needs of late-career faculty. A workshop on integrating technology into instruction for early-career faculty may need to cover different issues from one for late-career faculty. While some support services can include professors across age and rank, it is important to recognize that senior faculty also have their own distinctive needs that should be addressed in ways appropriate to their career stage and professional status.

$\checkmark$ Be cognizant of costs, but also of cost-effectiveness. In a time of constrained resources, it is easy to write off the development of senior faculty programs as too costly or not a good investment compared to developing early-career faculty. Many senior faculty 
development programs, however, may simply require the formation of workshops or learning communities that require minimal expenditure. Although there may be costs in developing some senior faculty support programs, it may be more costly to ignore this cohort of faculty and not receive maximum productivity in return. At every institution there are probably some senior faculty members whom administrators wish would simply retire. However, there are probably many more senior professors whom institutions want to retain as productive and engaged faculty members. Those are the senior faculty members whom administrators should work to keep energized, satisfied, and productive.

o Keep open lines of communication with senior faculty and develop mutually agreeable, clear, and consistent expectations. The latter stages of one's career can often bring uncertainty for both the individual faculty member and the institution. In order to maximize the talents of these faculty, clear expectations and goals can help alleviate some of the stresses of uncertainty. It can also help senior faculty members feel like valued members of the academic community if there are mutually agreeable opportunities identified for continued engagement, contribution, and productivity in the latter stages of one's career.

- Recognize the valuable contributions of senior professors and show your institution's appreciation. Late-career faculty sometimes feel neglected and unappreciated as their younger colleagues take over important teaching assignments, move into leadership roles, and gain stature through their research achievements and national service roles. While this developmental process is inevitable, it is important to acknowledge the valuable work senior professors continue to perform and recognize the significant contributions they have made over a long career. Academic leaders can support the morale of senior colleagues and their institutional community as a whole by recognizing the achievements of late-career professors with awards, citations, small grants, and personal notes that demonstrate the work of late-career faculty is visible and valued.

\section{Conclusion}

Senior faculty have a great deal to contribute to their institutions due to their years of experience, vast store of knowledge, and accumulated professional wisdom. This group of faculty also has its own distinctive challenges and needs. Many late-career senior professors can benefit from 
flexible forms of support to help them address those needs. This chapter outlines the varied ways institutions can assist senior faculty. However, support targeted specifically at senior faculty remains relatively rare across higher-education institutions. We hope this chapter provides a case for focusing more precisely on senior faculty. Colleges and universities cannot afford to waste any of their valuable human resources. Policies, programs, and services designed to support the work and careers of latecareer faculty can enrich the academic community by maintaining professors' vitality all the way to retirement.

\section{REFERENCES}

Appalachian State University Faculty and Academic Development. (2012). Senior faculty. Retrieved from hrtp:/hubbard.appstate.edu/senior-faculty

Association of Retirement Organizations in Higher Education. (2012). About AROHE. Retrieved from http://arohe.org/wp/about-us/

Austin, A. E. (2002). Preparing the next generation of faculty: Graduate school as socialization to the academic career. Journal of Higher Education, 73(1), 94-122.

Austin, A. E. (2003). Creating a bridge to the future: Preparing new faculty to face changing expectations in a shifting context. Review of Higher Education, 26(2), 119-144.

Baldwin, R. G., \& Chang, D. A. (2006). Reinforcing our "keystone" faculty: Strategies to support faculty in the middle years. Liberal Education, 92(4), 28-35.

Baldwin, R. G., DeZure, D., Shaw, A., \& Moretto, K. (2008). Mapping the terrain of mid-career faculty at a research university: Implications for faculty and academic leaders. Change, 50(5), 46-55.

Baldwin, R. G., \& Zeig, M. J. (2012). Making emeritus matter. Change, 44(5), 28-34.

Bataille, G., \& Brown, B. (2006). Faculty career paths: Multiple routes to academic success and satisfaction. Westport, $\mathrm{CT}$ : Praeger.

Berberet, J., Bland, C. J., Brown, B. E., \& Risbey, K. (2004, April). Preliminary report: Senior faculty perceptions and practices during the late career and planning for retirement. Paper presented at the TLAA-CREF Institute Conference, New York, NY.

Blaisdell, M. L., \& Cox, M. D. (2004). Midcareer and senior faculty learning communities. Learning throughout faculty careers. In M. D. Cox \& L. Richlin (Eds.), New directions for teaching and learning: No. 97. Building faculty learning communities (pp. 137-148). San Francisco, CA: Jossey-Bass. 
Bland, C. J., \& Berquist, W. H. (1997). The vitality of senior faculty members: Snow on the roof-fire in the fumace. ASHE-ERIC Higher Education Report 25(7). Washington, DC: George Washington University, Graduate School of Education and Human Development.

Boice, R. (1992). The new faculty member. San Francisco, CA: Jossey-Bass.

Brown, B. E. (2006). Supporting and retaining early-career faculty. Effective Practices for Academic Leaders, 1(9), 1-16.

Carleton College. (2012). Senior faculty development forum. Retrieved from https:/apps.carleton.edu/handbook/facultyapp/?policy_id=864379\#864439

Dartmouth College. (2012). Applications for faculty fellowships and senior faculty grants. Retrieved from http://www.dartmouth.edu/ dof/jjf_sfg _2011memo_rev.pdf

Gappa, J. M., Austin, A. E., \& Trice, A. G. (2007). Rethinking faculty work: Higher education's strategic imperative. San Francisco, CA: Jossey-Bass.

June, A. W. (2012, March 23). Aging professors create a faculty bottleneck. Chronicle of Higher Education. Retrieved from http://chronicle.com/article /Professors-Are-Graying-and/131226/

Marquette University Department of Philosophy. (2012). Policy for review of regular senior faculty. Retrieved from http://www.marquette.edu/phil /documents/SeFacRevProtocols.pdf

Ohio State University. (2012). University awards and recognition. Retrieved from http://www.osu.edu/universityawards/2012/scholar.html

Preparing Future Faculty. (2012). The Preparing Future Faculty Program. Retrieved from http:/www.preparing-faculty.org

Pruitt-Logan, A. S., \& Gaff, J. G. (2004). Preparing future faculty: Changing the culture of doctoral education. In D. H. Wulff \& A. E. Austin (Eds.), Paths to the professoriate: Strategies for enriching the preparation of future faculty (pp. 177-193). San Francisco, CA: Jossey-Bass.

Schuster, J., \& Finkelstein, M. (2006). The American faculty: The restructuring of academic work and careers. Baltimore, MD: Johns Hopkins University Press.

Trower, C. A. (2011). Senior faculty vitality. New York, NY: TIAA-CREF Institute.

University of Georgia Center for Teaching and Learning. (2012). CTL senior teaching fellows program. Retrieved from http://www.ctl.uga.edu/faculty /ctl_senior_teaching_fellows 